\title{
Investigação da Neurogranina como biomarcador de delirium em pacientes internados em unidade de terapia intensiva.
}

\author{
Felipe Dal-Pizzol ${ }^{1}$; Maria Vitoria Meller Milioli² ; Cristiane Damiani \\ Tomasi $^{3}$
}

\section{Resumo}

Neurogranina $(\mathrm{Ng})$ é uma proteína neuronal com importante plasticidade sináptica que age através da regulação da disponibilidade da calmodulina, sendo encontrada no líquido cefalorraquidiano e no plasma. Estudos prévios relacionam-na como possível biomarcador de quadros demenciais. Entretanto, seu papel na detecção de disfunção cerebral aguda nunca foi avaliado. O objetivo deste estudo foi avaliar a relação entre $\mathrm{Ng}$ e delirium em pacientes internados em unidade de terapia intensiva (UTI). Foi avaliado o nível plasmático de $\mathrm{Ng}$ nos dias da internação e do desenvolvimento de delirium de 45 pacientes da UTI do Hospital São José, em Criciúma/SC, no período de junho de 2013 a junho de 2014, excluindose internações inferiores a 24 horas ou por causa neurológica. Foi visto que a $\mathrm{Ng}$ medida no dia da internação é significativamente maior naqueles que desenvolveram delirium, quando comparada aos que não. Entretanto, não há uma variação significativa entre os níveis de $\mathrm{Ng}$ quando realizado delta entre internação e sangue coletado no dia do desenvolvimento de delirium. Concluiu-se que a Neurogranina pode ser um biomarcador precoce de delirium em pacientes criticamente enfermos.

Palavras Chave: neurogranina; delirium; biomarcador

\footnotetext{
${ }^{1}$ Doutor em Ciências Biológicas (Bioquimica) pela Universidade Federal do Rio Grande do Sul (2001). Atualmente é vinculado ao PPG Ciências da Saúde da Universidade do Extremo Sul Catarinense e bolsista de Produtividade em Pesquisa do CNPQ.

2 Graduanda em Medicina pela Universidade do Extremo Sul Catarinense e bolsista de Iniciação Científica do CNPQ.

${ }^{3}$ Doutora em Ciências da Saúde pela Universidade do Extremo Sul Catarinense (2014).
} 


\section{Referências}

DIEZ-GUERRA, F.J.; Neurogranin, a link between calcium/calmodulin and protein kinase C signaling in synaptic plasticity. In: IUBMB Life. Madrid: UAM, 2010. V. 62. p.597-606.

DE VOS, A. et al.; C-terminal neurogranin is increased in cerebrospinal fluid but unchanged in plasma in Alzheimer's disease. In: Alzheimer's \& Dementia: The Journal of the Alzheimer's Association. Gent: ADx NeuroSciences NV, 2015. V. 11. n.12. p.1461-1469. 